\title{
Curriculum, instructional design and the technologies: Planning for educational delivery
}

\author{
Clare McBeath \\ Curtin University of Technology, Western Australia \\ Roger Atkinson \\ Murdoch University, Western Australia
}

\begin{abstract}
There has been a tendency in the past for people to see curriculum development, instructional design and the technologies used for educational delivery as three different, but complete, approaches to the output of learning materials. At times there has been inadequate communication and even antagonism between the practitioners of the different fields. Each field views its own expertise as all encompassing and able to perform all that is required in the production of educational programs and materials. This paper examines these three areas of expertise, describing their backgrounds, analysing the different types of responsibilities and looking for definable interfaces between them. It presents a layered model, wherein each layer has an interrelating place as part of a holistic approach to the production of good educational materials. Examples are given to illustrate the requirements, limitations and opportunities offered by each layer of the model to those above and below it.
\end{abstract}

\section{The diversity of educational delivery}

A vast number of people work in the area of design and delivery for education and training. Teachers, lecturers, instructors, trainers and tutors deliver face to face education in traditional classrooms, seminars, or study groups; curriculum developers produce occupational and needs analyses, design syllabus documents, learning materials, dissemination strategies and evaluation instruments; instructional designers produce media and teaching materials, structure learning patterns and processes and design 
learning packages; technologists design computer aided instruction, interactive videodiscs and educational telecommunication applications. The diversity is endless. The people involved come from many different educational backgrounds and represent a wide range of disciplines, ideologies and experiences.

While the design and delivery of education might seem to people outside the field as a fairly homogeneous activity, we who work in the area know that the range of practice has spawned a remarkable lack of common purpose. At times there is antagonism between the practitioners from different fields, instead of productive teamwork. Indeed, each may view its own expertise as all encompassing and able to perform all that is required in the production of educational and training programs. The following quotations indicate part of the problem.

Educational technology means the whole process of finding solutions to the practical problems of teaching and learning (Committee on Open

University, 1974, p.71).

The term curriculum covers matters relating to the arrangements [institutions] make for students' learning and development. It involves the content of courses, student activities, teaching approaches and the ways in which teachers and classes are organised (Joint Schools/TAFE Committee, 1990, p.27).

... what in one country is called educational technology may in another be called instructional design (Strain and Inglis, 1991, p.2).

We could present many such definitions, but we already have our key terms, curriculum, instructional design, and educational technology. These terms do not necessarily have an exact identification with specialists in instructional technology, educational media, interactive multimedia, hardware and software, curriculum planning, needs analysis, and so on. Successful conduct of projects depends upon productive teamwork between these three broad areas and upon negotiated boundaries, which may vary from one project to another.

The purpose of this paper is to build a model using the functions and practices of curriculum, instructional design, and educational technology, without needing to be precise about their boundaries. In fact there are real problems with all these terms.

There is a problem with the term curriculum. It still has overtones of things that happen in schools and is not a word used easily in industry and commercial training, although it is interesting to note that the new state administering agencies for recognition of training and the Australian Committee for Training Curriculum use the term openly and without apology (ACTRAC, 1992). Many use instructional design synonymously 
with curriculum development. Others use it to describe page design or use of graphics. Educational psychologists might think of instructional design more in terms of improving learning processes and strategies.

We considered alternatives to the term educational technology, because of its elasticity of definition and the way its meaning is changing (Strain and Inglis, 1991). It is a popular term, frequently used without clear agreement of meaning. It interweaves the theory and practice of the other fields and practitioners in each claim to have some ownership of educational technology. It may have functions in common with the areas with which we are dealing and it is a tool for the overall objective of curriculum, instructional design and technological applications in education, that is, successful learning.

We chose eventually to use these three terms as most closely establishing the extent of the functions or responsibilities which we wish to discuss.

\section{How the diversity came about}

Curriculum development, instructional design and educational technology, while remaining three distinct fields, constantly spill over loosely defined borders and hoist their flags in each other's patches. It is useful to distinguish between them in terms of their history, their perspectives and their impetus in the production of the instructional message.

Curriculum development had its roots in educational method and administration, the philosophy and sociology of education and to a lesser extent in management theory. It has two main branches of ideology, one systems oriented, or technological (Tyler, 1949; Taba, 1962; Popham and Baker, 1970; Gagne, 1978), and the other naturalistic (Walker, 1971; Taylor, Reid and Holley, 1974; Eisner, 1979). It deals with the planning, development and delivery of instruction, including technological delivery systems, based on defined social, economic, political and personal needs. Curriculum developers are usually teachers, trainers or administrators.

Instructional technology is based on psychology, from both the operant behaviourist and the cognitive school. The adherents of each camp "rarely cite, much less read each other's work" (Becker, 1991). The central premise of the cognitive approach is that learning media are built around student learning processes and their symbol systems are organised to maximise those processes (Kozma, 1991). It presupposes active collaboration of the student with a given medium to construct knowledge. The behaviourist approach, on the other hand, sees learning occurring as the result of instruction being delivered by some medium, in the sense of the stimulus creating the response. Instructional designers are usually influenced by educational psychology. 
The designers who study the application of instructional design through whatever media are appropriate, according to defined principles of student need and student learning processes, fall into one definition of educational technology. There are also the technologists, the creators of technological tools for teaching and learning; those concerned with the selection and operation of equipment and software; people who use email and bulletin boards, audiographics and communication systems. In this group we have an unlikely mix of engineers and whiz kids, artists and isolates.

Reality is not so simply described, but the essence of the problem is clear. From different ideological backgrounds, trained in a wide variety of disciplines, using language and concepts unfamiliar to others, an army of instructors, psychologists and technologists roam the field of educational delivery.

Curriculum developers are equipped to examine the needs of students, social and demographic patterns, the demands of governments, industry, unions, and technological change, the limitations of space, finance, time and teachers. The field of curriculum also claims that instructional design and the development of media lie within curriculum practice, informed by needs and occupational analysis. They stray happily into instructional design and technological applications, bringing those concepts and principles to bear on the definition of needs, design strategies, materials development and course evaluation, and the principles of curriculum, in turn, on their approach to design and technology. Instructional designers likewise claim to possess a complete set of tools for the delivery of instruction, but informed by learning principles and processes (Parer, 1989). They are often technologically literate and are equally at home with print, audio and video technologies, computer assisted learning, interactive videodisc and similar resources. Educational technologists may also have curriculum or instructional design skills, but frequently are operators who aim to produce the best mix of technologies for the task on hand. Sometimes they are experimenters, inventors and creators of technologies, waiting for opportunities to display or market their talents.

There are many shared skills and functions in these three specialist areas, but there are also numerous barriers. Technologists may speak a language nobody outside their specialist areas can understand, knowing that their products are in the forefront of knowledge and wondering why they are not being used more extensively. Designers complain about the ugliness of much of the technological product and are not interested. Curriculum developers criticise the lack of planning and analysis, and the waste of time and effort, when a good educational program is perfected in isolation from defined market need or when there is no budget to put it into practice. 
It is not only a problem of language and ideology, however. It is also one of organisation. Organisational patterns of behaviour in education and training are usually conservative and often biased. Curriculum developers in a Ministry of Education, for instance, tend not to interpret their task outside traditional schools based delivery. They are locked in to view their role in one set way, and may not recognise the curriculum implications of a low cost audiographics system for use in rural schools, for instance. Such a project goes to another section and may not have the impact it should on mainstream curriculum development.

The same sort of organisational barriers exist in universities. A school of computer engineering might attract large grants from government or industry, but its traditional pattern of organisation mean that these funds are poured into more experimentation, more $\mathrm{PhD}$ students or more expensively equipped laboratories. Organisational structures inhibit sharing it, for example, with a school of education or an educational media unit. The perspectives of other practitioners and their knowledge of the end use, and the end users, are not only alien but not considered.

The situation is repeated in the technical and further education sector (TAFE). Typically there is a curriculum branch for designing subjects and courses, a computer section for selecting and buying computers, instructional designers attached to the distance education college and educational technologists engaged in open learning and CAI projects. All the ingredients are there, but often there is little in the way of an integrated project management approach.

The use of developers in the training functions of industry is even less focused, often following the personal propensities and interests of a single Senior Training Officer, who creates an environment, or ethos, which his staff follow. Good work is being done exploring the technologies or using one or other approach to the learning process, but rarely seeking expertise from a wider pool of professionals outside the company. Academics are distrusted and educationalists are seen as unsophisticated in the realities and pressures of the workplace. Industrialist and academics have trouble establishing a platform of meaning about education and tend to think much differently from each other about funding, deadlines and quality matters.

If the organisational structure inhibits communication and team work within the various sectors, this is even more of a problem when it comes to cross sectoral developments. All too often training development projects or government funded initiatives are not conceived in terms of structured teams with a set of essential skills and functions crossing traditional demarcation lines. Yet this is exactly what we believe should be happening. 


\section{The layered model}

Our model perceives curriculum planning, instructional design and the design and use of learning technologies as three "layers", linked by two types of interactions. Each layer offers opportunities and limitations to the layer above it, and generates requirements for the layer below it.

Above and below the defined layers are many further layers outside the field of education or training. Outside, or "above" curriculum are governments, institutional management and broad societal factors such as economic reform, demographics, industry restructuring and so on. Outside, or "below" educational technology are the various branches of engineering, satellites, Telecom, IBM and Apple and other multinational firms, and a rich array of rapidly developing technologies. The layered model recognises these as powerful forces, or influences, but they are not part of the workface of delivering education and training.

The purpose of the layered model is to provide a conceptual framework for project organisation. It seeks to emphasise an integration of the contributions from curriculum development, instructional design and the technologies. The composition of the UK Open University course teams, for example, provided such an integration by mixing together subject experts, specialists in instructional design and BBC producers.

Each layer has a unique set of concepts, insights and functions within itself. Each also has both opportunities and limitations to offer to the practitioners in the layer above. Each layer generates requirements to be fulfilled by the layer below. Requirements interact with the limitations and opportunities to further the overall goal of well planned, realistically delivered and productive learning programs.

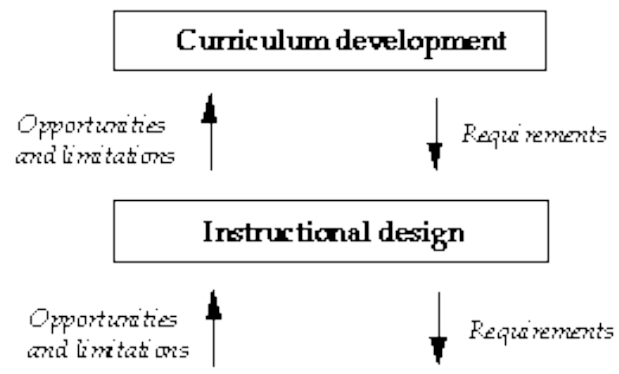

Educational technology

The layered model 
The concept of layers is derived by analogy from a common convention in communications, that the lowermost layers are closest to the hardware and the topmost layers closest to the end users. The model may be viewed also as a hierarchy in the sense that the topmost layer is the most closely linked to management. It does not imply a ranking in importance, or a sequence of activities, but it does assert that this range of functions is essential. In general this requires assembling a team of complementary experts, although project managers may find individuals with expertise in more than one layer, or in all three.

Within this framework, and to illustrate the layered model, we discuss three Western Australian projects. Each of these may give some insight into the broad problem of integrating the contributions of curriculum development, instructional design and the technologies. These projects, or development areas, are telematics for rural schools, educational video conferencing, and the Japanese Language Interactive Videodisc project. By international standards, these are relatively small experimental developments, with little scope for access to large scale integration of curriculum development, instructional design and the technologies, compared with the framework available, for example, to the UK Open University's course teams.

\section{Telematics for rural schools in WA}

A project in telematics for teaching secondary subjects in rural schools is being undertaken currently by the WA Ministry of Education's Distance Education Centre. The term telematics, established in Australia largely by the efforts of project teams in the Victorian Ministry of Education and Training (Elliott, 1991; Conboy, 1990; D'Cruz, 1990), refers to the delivery of lessons to remote classrooms by audiographic teleconferencing. The technological tools include Telecom PSTN telephone lines, loudspeaker telephones or audio teleconferencing units, facsimile machines, Macintosh computers, $2400 \mathrm{~b} / \mathrm{s}$ modems, digitising pads with styluses, and The Electronic Classroom software. Developed commercially in Australia by Revelation Computing Pty Ltd, this software communicates keyboard, mouse controlled or stylus text and drawings, or previously prepared displays from disk, to remote sites via a modem port. Remote sites may make similar transmissions to the central site, and multi pointing is possible if the central site's Macintosh has multiple serial ports, modems and telephone lines.

From the educational technology perspective, system design and installation is not especially daunting. The equipment and software is relatively economical, reliable, readily available, easy to use, and well proven by experiences in Victoria. Choosing modems, fax machines, particular types of Macintosh computers, handsets or audio 
teleconferencing units, and arranging telephone line installations are not major technical tasks. Modest upgrades may be made to the basic installation, for example, to accommodate larger groups at each site, or for multi pointing. The software is from a commercial developer, and at present has no established MS DOS or Windows competitor at realistic prices. Audiographic installations are a relatively low risk, because the overall cost of hardware and software is low, because systems have been developed elsewhere in a similar context, and because the major items, such as Macintosh, fax and modem, can be used also for other functions in small rural schools.

The limitations imposed on the instructional design layer by simple audiographics technology are clear by comparison with traditional classroom delivery. Audiographics must be complemented by print and other resource materials, by support from a local resource person or supervisor and by occasional visits from the teacher. Another limitation is that teachers and students need to be trained to use the technology. On the other hand, audiographics provides the opportunity for instructional designers to enhance traditional correspondence schooling. It narrows the gap between correspondence teaching and the more familiar world of lesson design for the classroom. It also lightens the instructional design load of preparing print, videotape and other resources which would normally be used for correspondence teaching. Experiences elsewhere give confidence in the feasibility of successful instructional design for this type of audiographics. The requirements imposed on the technologies by instructional design include reliability, ease of use, and providing flexibility of interaction between teacher and student (Elliott, 1991).

Design considerations in turn generate a set of limitations and opportunities for curriculum development. Teachers, students and parents need educating about a new type of instructional design, and reassurance that examination rankings and other outcomes are comparable with other methods. There may be a need for changes to lower school curricula to make room for specific learning about technologies and the new type of classroom to be used in later years of study. Timetabling, providing a room for telematics activities, organising complementary print and other materials, budgeting and similar important details need attention. The balance between centralised and regionalised services (Hull and Dean, 1988 ) is a responsibility for the curriculum layer. However, there is a very significant opportunity provided, to deliver an improved and affordable service to the smaller rural centres which would otherwise have to suffer the closure of their local school, very long bus trips, sending children to boarding schools, or more dropouts in the rural sector. These considerations could be described equally well as requirements imposed on instructional design by the curriculum development layer, a requirement to do something about the problem. 


\section{Video conferencing in WA}

Video conferencing facilities are being developed at Curtin University (4 sites), Murdoch University (1 site) and WA TAFE (7 sites). The technology provides two way live video and audio communication between two sites, using digitalised compressed signals transmitted at $128 \mathrm{~kb} / \mathrm{s}$ over two ISDN channels (Atkinson, Latchem and Davy, 1991; Mitchell, 1991; Horner and Reeve, 1991). Graphics transmission, near end equipment control panel and far end remote control are options which are likely to be used by all sites. Although equipment and technologies are available for multi point operations, and for connections using up to six ISDN channels for higher quality, these options not at present used in WA because the additional costs are high.

Considered as a task within the educational technology layer, system design and installation for video conferencing is much more complex than is the case with audiographics (Mitchell et al, 1992). The equipment cost per site is about $\$ 95,000$ compared with telematics at $\$ 6,000$ to $\$ 10,000$ per site. There is a risk that funds may not be used to the best advantage, because at present we do not have a useable international standard to provide connectivity between different manufacturers' equipment in the most widely used configuration, that is, a bit rate of $128 \mathrm{~kb} / \mathrm{s}$ with ISDN networking accessed by Microlinks with $2 \times 64 \mathrm{~kb} / \mathrm{s}$ channels. The technology is not fully mature and further significant changes may occur. Rural and remote areas may have to wait several years to be connected to ISDN by means of the most relevant type of access.

The predominant limitation handed up to the instructional design and curriculum development layers arise from the high cost, high risk nature of the technology. Design for use of video conferencing is not just a matter of design for remote classroom delivery. It includes design for communications by administrative, research and staff development users, and by industry and government clients. Sharing with other users, in addition to an institution's own students and staff, is essential because of the high fixed costs incurred. Therefore, instructional design has to be broadened to include design of presentations, design of committee meetings, and support services which assist in the recruitment of clients from industry and government. Graphics transmission and user friendly control panels are technological options which facilitate the instructional designer's task, and these could be described as requirements handed down to the technological layer. Another requirement handed down is the importance of maximising the number of compatible sites, because the larger this number, the easier the task of recruiting clients from outside one's own organisation.

On the other hand, video conferencing technology provides the opportunity for remote communications which are more closely equal to face to face 
communications than any other technology. It provides scope for an integrative instructional design, which in broad terms is conventional print and tape media to deliver lectures, whilst video conferencing delivers tutorials, the most interactive part of traditional teaching. In colloquial terms, we could say that Australia Post gets the lecture delivery traffic, and Telecom gets the tutorial delivery traffic.

Video conferencing is one case in which the implication of hierarchy in the layered model may be drawn upon. The most significant limitation, the risk of failing to achieve a justifiable cost effectiveness, can be handed up to the curriculum layer and its links with senior management and government. Given the high cost, small scale networking within regions, or within one institution, is unlikely to be sufficient, in contrast to telematics. Utilisation of the medium requires consortium approaches, integration with the many other activities and delivery strategies undertaken by institutions, and the introduction of commercial clients. Paying the bills, timetabling of site and network hours, staff development for users, organisation of support services, appointment of specialist staff, and recruiting of commercial clients are complex and time consuming curriculum matters. It is not feasible to hand down to instructional design and the technologies the simple requirement that it is their responsibility to make it work. A more useful set of requirements would include evaluation guidelines, especially the monitoring of costs, and requirements for reporting and publishing the details of the experiences gained, as befits an experimental development.

\section{The Japanese Language Interactive Videodisc Project}

Illustrations of the layered model do not have to be confined to the sequence of technologies, instructional design and curriculum development. The Japanese Language IV Project is a good case in which the opposite sequence may be illustrated. This project arose from an opportunity presented by the Federal Government's Reserve Fund. For the 1990 awards it was evident that strong support would be available for technological innovations related to specific areas of curriculum development. A grant of $\$ 310,000$ was made to the WA Distance Education Consortium for 1990-91. Whilst the submission was made with a knowledge of the curriculum development picture, and the opportunities and limitations presented by the instructional design and technology layers, in retrospect it seems that a very difficult and challenging requirement was handed down. This contrasts with video conferencing, in which the carrying of risk was represented as a limitation handed up. For the IV project, the instructional design and technology layers in WA had to be created from very small nuclei. That has been done successfully but it required intense work from the persons involved (Temple, Pinfold, Latchem and Fox, 1992; Fox, Latchem and Pinfold, 1992; Temple and Borzyskowski, 1992). 
Also in retrospect, it is difficult for one opportunity handed up to be accommodated. This is the question of whether the project team and their skills will be put to use in further projects.

\section{Conclusion}

The 1990s usher in new perspectives and new opportunities for the planning and designing of educational programs. New levels of accountability require better management of projects. New technologies call for new ideas and greater adaptability.

Team work, shared practice and cooperation are more necessary than ever before to keep our educational and training courses competitive and relevant in rapidly changing markets.

It is time that curriculum developers, instructional designers and those concerned with the technological delivery of the educational message shift their perspectives towards viable, creative teams, intent on solving the problems of learners, rather than the self aggrandisement, or isolation of individual practices. They need to recognise the role of each layer in the overall process and the importance of real interaction between them. Planning teams need to be generous and open minded in their acceptance and inclusion of representation from each area. The present climate of economic efficiency at a time when technological opportunity is greater than ever before, indicates that teamwork is an essential ingredient of all major educational innovation.

There needs also to be better recognition and understanding by those outside, those above and below our model, that these layers of expertise exist and need to feed into the educational and training decision making process. For large projects involving funding from governments and industry, the proponents of new technologies must learn to work with and through the existing layers of the educational area and not rush into poorly understood and poorly developed educational schemes based on politics, quick profits, whizbang technologies or other forms of empire building. One purpose of the layered model is to emphasise the need for a balanced and wide ranging approach to project planning, project management and team building processes. Another purpose is to help structure relationships between industy and institutions when contracts to provide open learning materials and services for industry training needs are undertaken.

The model is probably not yet complete. It was developed partly on the case studies used in this paper. No doubt further work could identify a much more complex interactivity of opportunities, limitation and requirements up and down the layers. The point, however, remains that far 
reaching development in the use of technologies in education can only occur when practitioners in curriculum, instructional design and educational technology put aside their differences, learn to respect each other's expertise and share their knowledge professionally and generously.

\section{References}

Atkinson, R., Latchem, C. and Davy, G. (1991). Live-Net and beyond: A universities and TAFE video conferencing consortium in WA. In R. Atkinson, C. McBeath \& D. Meacham (eds), Quality in distance education: ASPESA Forum 91. Bathurst, NSW: ASPESA.

Australian Committee for Training Curriculum (ACTRAC). (1992). User's guide to course design for competency based curriculum. Canberra: ACTRAC.

Becker, Wesley C. (1991). Towards an integration of behavioural and cognitive psychologies through instructional technology. The Australian Journal of Educational Technology, 7(1), 1-18. http: / / www.ascilite.org.au/ajet/ajet7/becker.html

Committee on Open University. (1974). Open tertiary education in Australia: Final report of the Committee on Open University to the Universities Commission. Canberra: AGPS.

Conboy, I. (1990). Teaching with Telematics: It's not as hard as it looks, or is it? In J. G. Hedberg, J. Steele and M. Mooney (eds), Converging Technologies: Selected papers from EdTech'90, 14-23. Canberra: AJET Publications. http: / / www.ascilite.org.au/asetarchives/confs / edtech90/ conboy.html

D'Cruz, J.V. (1990). Technology in education: a study of policy and practice in rural schools. Melbourne: Ministry of Education, Victoria.

Eisner, Elliot W. (1979). The educational imagination. New York: Macmillan.

Elliott, Neil. (1991). The telematics manual, Victoria. Bendigo, Victoria: Ministry of Education and Training.

Fox, Robert, Latchem, Colin, \& Pinfold, Christy. (1992). An instructional model for multimedia language learning: A case study. In Proceedings of the International Interactive Multimedia Symposium 1992, 71-74. Perth: Promaco Conventions.

Gagne, Robert M. (1978). The scientific basis of the art of teaching. New York: Teachers College Press.

Horner, David, \& Reeve, Ian. (1991). Telecottages: the potential for rural Australia. Canberra: AGPS and Department of Primary Industries and Energy.

Hull, Daryll \& Dean, Tony. (1988). Future directions for the Distance Education Centre: Strategic planning study. Perth: Ministry of Education WA.

Joint Schools / TAFE Ministerial Post-Compulsory Education Taskforce. (1990). Adjusting to the future. Perth: Ministry of Education WA. 
Kozma, Robert B. (1991). Learning with media. Review of Educational Research, 61(2), 179-211.

Mitchell, J. et al. (1992). Evaluation of the use and potential of video conferencing facilities within the higher education sector in Australia. Consultant's report to the Department of Employment, Education and Training.

Mitchell, John. (1991). The TAFE video conferencing breakthrough. In R. Lundin (ed), Australian Teleconferencing Directory 1991. Brisbane: Queensland University of Technology.

Parer, Michael S. (ed). (1989). Development, design and distance education. Churchill, Vic: Centre for Distance Learning, Gippsland Institute.

Popham, W.J. \& Baker, E.L. (1970). Systematic instruction. New York: Prentice Hall.

Strain, James, \& Inglis, Alistair. (1990). What's in a name? That which we call a course by any other name would smell as sweet. Australian Journal of Educational Technology, 6(1), 1-11. http: / / www.ascilite.org.au/ajet/ajet6/strain.html

Taba, Hilda. (1962). Curriculum development. New York: Harcourt Brace Jovanovich.

Taylor, P.H., Reid, W.A. \& Holley, B.J. (1974). The English sixth form: A case study in curriculum research. London: Routledge \& Paul.

Temple, Anthony, \& Borzyskowski, George. (1992). The look and feel of multimedia: Three interactive case studies. In Proceedings of the International Interactive Multimedia Symposium 1992, 149-156. Perth: Promaco Conventions. http:/ / www.ascilite.org.au/asetarchives / confs / iims / 92 / temple1.html

Temple, Anthony, Pinfold, Christy, Latchem, Colin \& Fox, Robert. (1992). Language Partner - Japanese 1: A case study in cooperative multimedia courseware development. In Proceedings of the International Interactive Multimedia Symposium 1992, 157-167. Perth: Promaco Conventions. http: / / www.ascilite.org.au/aset-archives/confs / iims / 92/temple2.html

Tyler, Ralph. (1949). Basic principles of curriculum and instruction. Chicago: University of Chicago Press.

Walker, Decker F. (1971). A naturalistic model for curriculum development. School Review, 80(1), 51-65.

Authors: Dr Clare McBeath is a Senior Lecturer in Curriculum Studies at Curtin University of Technology, GPO Box U1987, Perth, Western Australia 6001. (C.McBeath@ed.curtin.edu.au)

Dr Roger Atkinson is the Acting Director of External Studies, Murdoch University (atkinson@cleo.murdoch.edu.au).

Please cite as: McBeath, C. and Atkinson, R. J. (1992). Curriculum, instructional design and the technologies: Planning for educational delivery. Australian Journal of Educational Technology, 8(2), 119-131. http: / / www.ascilite.org.au/ajet/ajet8/mcbeath.html 